\title{
Joyful, Joyful, We Love Singing: Teaching Foreign Language and Culture with Musical Mnemonics
}

\author{
Erin Noelliste \& Joseph Noelliste
}

\begin{abstract}
Mnemonics have long been considered a useful tool for enhancing shortand long-term recall. For example, most American children learn the alphabet by singing the letters to the tune of Twinkle, Twinkle, Little Star, and many elementary school students memorize states and capitals by utilizing songs written specifically for this purpose. The present paper discusses how musical mnemonics can enhance teaching of foreign language and culture through the writing of new lyrics to well-known tunes. The paper presents popular mnemonic devices used in German L2 classrooms and provides a step-by-step compositional framework using syllabic structure for the creation of original mnemonic songs for new topics in any language.
\end{abstract}

\section{Introduction}

During antiquity, memorization emerged as a critical sub-study within the art of rhetoric as shown by a number of important treatises on the topic, such as Aristotle's De memoria atque reminiscentia, Cicero's De oratore, and Quintillian's Institutio Oratoria (Vatri 2015). In the Middle Ages, an adept memory continued to be considered "an important characteristic of the most esteemed scholars," and its mnemonic enhancers proliferated throughout "medieval philosophy and pedagogy... [as] predecessors of objective thinking" (Packard \& Chen 2005). One such example is the famed Guidonian Hand, a mnemonic invention by eleventh-century Benedictine monk and music theorist, Guido d'Arezzo, which used the human hand to both embody and simplify the intricate melodic systems of the day (Killam 1988). Although prevalent for centuries, memory enhancement seems less central to modern pedagogical practices (Putnam 2015); however, recent scholars have studied the influence of music in enhancing memorization in foreign language education (see, for example, Purnell-Webb \& Speelman 2008, Good et al. 2015, among others). This research shows that students who utilize lyrics set to music in order 
to memorize key concepts have significantly better long-term recall when compared to students who rely primarily on rote memorization techniques.

The present paper uses musical examples and basic mnemonic song writing strategies to demonstrate how music fortifies the retention of principles learned in the language classroom. A step-by-step guide for creating new mnemonic musical devices for the language classroom is presented, and the excellent opportunities for cultural engagement in the lesson afforded by these new mnemonic devices are discussed. Featured musical examples may be heard at the YouTube links included throughout. The techniques demonstrated in this paper are based on workshops conducted at the SCENARIO Forum Conference in May of 2017 at the University College Cork, Ireland and the 5th SCENARIO Forum Symposium on Performative Pedagogy at the University of Northern Colorado in January of 2018.

This paper is organized as follows: Section 2 highlights various forms of mnemonic devices, including musical examples. Section 3 discusses ways that melodies are frequently adapted to fit multiple texts. Section 4 presents examples of musical mnemonic devices commonly taught in the L2 German classroom and outlines steps for the creation of new examples. Section 5 concludes.

\section{Various Types of Mnemonic Devices}

Mnemonic devices increase connections of a given concept with other mediums (such as images, acronyms, or melodies) in order to enhance memory and recall through a richer associative network. These multiple connections stimulate quicker and more permanent, long-term recall of information. The foundations of mnemonic technique were established in Ancient Greece, and the term itself originates from Mnemosyne, the goddess of memory in Greek mythology (Yates 1996). As such, mnemonics have had a long history in education, and a number of techniques have developed, such as link method, method of loci, peg system, keyword method, phonetic system acronyms, and acrostics, as well as songs, stories, and rhymes (Putnam 2015).

Many mnemonics used in education are visual; that is, they associate a concrete concept with a visual representation. For example, the Guidonian Hand (see figure 1), referred to in the introduction, is a method for visualizing musical notes which are placed at specific points on the hand. Students memorize the association between the assigned points on the hand and the affiliated notes in order to become proficient in sightsinging. Functioning as an early form of solfege, teachers would help students sightsing by simply pointing to the notes on their hand; specifically, teachers would point to various places on their own hand, and students would then vocalize the melody based on the notes positioned in these particular places (Killam 1988). Similarly, many contemporary music educators use particular hand motions associated with specific solfege syllables to help their students sightread new music (Frey-Clark 2017). Another common visual mnemonic is using the knuckles on a hand to 
determine the number of days in each month of the year. With this mnemonic, each knuckle represents a month with 31 days, and the space between each knuckle represents a month with 28 or 30 days. By starting on the pinky knuckle, one can then count January with 31 days, February (in the space between the knuckles) with 28 days, the next knuckle, March, has 31 days, and so on.

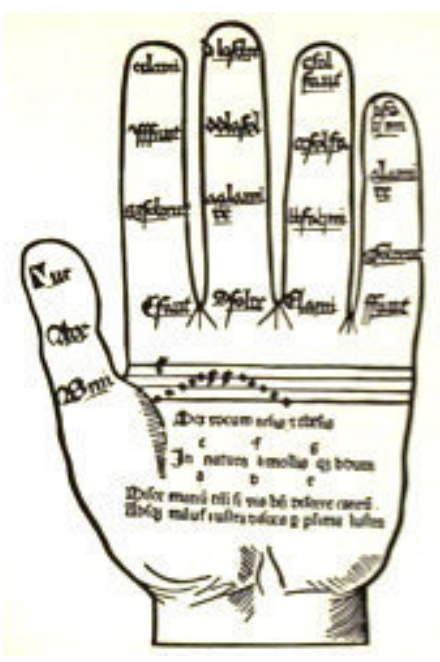

Figure 1: Guidonian Hand

Another common form of mnemonics is acronyms. For example, when learning the order of the colors in the rainbow, children often memorize the acronym ROYGBIV, which represents the colors red, orange, yellow, green, blue, indigo, and violet. When learning to read musical scores, young music students often encounter the phrase (or a similar derivative) every good boy deserves fudge, which represents the sequential treble clef lines E, G, B, D, F (see figure 2).

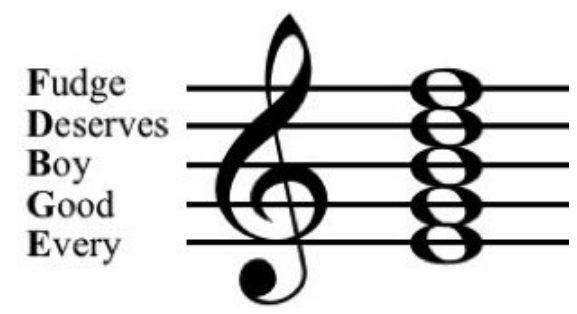

Figure 2: Acronym for Notes in the Treble Clef

Finally, musical mnemonics are often employed in educational contexts in an effort to actively engage students while helping them memorize longer sequences of words or larger amounts of content. For example, American children are typically taught the alphabet to the tune of Twinkle, Twinkle, Little Star. There are also several songs which have been written specifically to help American elementary school children memorize the 50 U.S. states, such as the one penned by Animaniacs to an adaptation of the traditional English folk tune 
Rose Tree. From the 1970's through the 1990's, Saturday morning children's television programming included the series Schoolhouse Rock! on the American television channel ABC. Each three-minute Schoolhouse Rock! video contained a song with lyrics explaining concepts pertaining to mathematics, grammar, and science, among others.

While the majority of the examples of musical mnemonics listed above generally target elementary school children, there are many benefits to singing in the classroom for any age group, and recent research has targeted the benefits associated specifically with the language classroom. Some of the benefits of singing in the L2 include:

- Enhanced short-term and long-term recall (Good et al. 2015)

- Increased engagement from students (Good et al. 2015)

- Support for group health (Livesey et al. 2012)

- Improved pronunciation (Good et al. 2015)

- Fortified translation skills (Good et al. 2015)

- Invigorated cultural experiences (Livesey et al. 2012)

It is clear from the literature cited above that singing in the L2 enhances many aspects of the learning experience. One opportunity for increasing singing in the L2 while concurrently promoting retention of language concepts is to incorporate musical mnemonic devices in the curriculum. To that end, the following sections present techniques for creating new musical mnemonic devices, which are based on principles for adapting melodies from the field of hymnology.

\section{Melodic Manipulation}

At the back of hymnals used in traditional corporate worship of most Christian mainline denominations, there is an index of hymn meters, which include a series of numbers written next to each hymn title. These numerical sequences essentially identify the syllabification or meter in which a hymn text is written. Although there are a wide variety of hymn meters, most hymns fall into the following three: Common Meter (8.6.8.6), Long Meter (8.8.8.8), and Short Meter (6.6.8.6) (Watson 1999, Chapter 2). Various hymn melodies are also written to correspond to these meters. In this way, any given hymn text written in a particular meter can be set to a melody in the same meter. Thus, if a congregation were familiar with just three hymn tunes, one from each of the above meters, they would have the ability to sing many hymn texts within those meters. In this paper, the principle of matching various texts with melodies which contain the same syllabic structure will be described as tune equivalency. 
Examples of how tune equivalency can be applied to popular texts and melodies are given in the following section. Prior musical knowledge is not required to understand the methodology given below. However, readers who possess musical background and have familiarity with this melodic concept may elect to skim the following section.

\subsection{Tune Equivalency}

In 1779, John Newton first published one of the most famous common meter hymns, Amazing Grace, in a hymnal resource he co-wrote with William Cowper entitled Olney Hymns. Each of its four-line stanzas is syllabified as 8.6.8.6 as shown in (1), where the first and third lines have eight syllables, and lines two and four have six syllables each.

\begin{tabular}{|ll|}
\hline Amazing grace how sweet the sound & 8 \\
That saved a wretch like me. & 6 \\
I once was lost but now am found. & 8 \\
Was blind but now I see. & 6 \\
\hline
\end{tabular}

Figure 3: (1) Meter of Amazing Grace

Another popular melody in Common Meter is the theme song to the 1960's American television sitcom Gilligan's Island, written by Sherwood Schwartz and George Wyle. The meter for this melody can be seen in (2).

\begin{tabular}{|ll|}
\hline Just sit right back, you'll hear a tale & 8 \\
Tale of a fateful trip, & 6 \\
That started from this tropic port & 8 \\
Aboard this tiny ship. & 6 \\
\hline
\end{tabular}

Figure 4: (2) Meter of The Ballad of Gilligan's Isle

As these two texts, and the melodies to which they are traditionally set, are both in Common Meter, one could theoretically "mix and match". That is, based on the principal of tune equivalency, a person could sing the words of Amazing Grace to the tune of the theme from Gilligan's Island, or conversely sing the words of the theme to Gilligan's Island with the melody of Amazing Grace. Additionally, entirely new lyrics set to the 8.6.8.6 syllabic structure of common meter could be sung to either melody.

\subsection{Tune Adaptation}

While the examples for tune equivalency in section 3.1 showed a direct one-to-one correlation between the texts and melodies of Amazing Grace and The Ballad of Gilligan's Isle, this may not always be the case for texts intended 


\begin{tabular}{|cc|}
\hline $\begin{array}{c}- \text { Hast du et }- \text { was Zeit für mich } \\
\text { Praise God from whom all blessings flow }\end{array}$ & 8 \\
\hline
\end{tabular}

Figure 8: (6) Subtraction

\section{Musical Mnemonic Devices}

\subsection{Common Devices Used in the German L2 Classroom}

As discussed in section 2, musical mnemonic devices are often used in educational contexts to teach children various concepts. Application of these devices also extends beyond elementary classrooms to include L2 learning environments. Several examples of musical mnemonics commonly taught in the L2 German classroom are presented in this section.

Like the English alphabet, the German alphabet can be set to the tune of Twinkle, Twinkle, Little Star with some necessary tune adaptation techniques applied near the end of the alphabet with the letters $\mathrm{w}, \mathrm{x}, \mathrm{y}, \mathrm{z}$, as the names for several letters differ in syllabic structure between the languages. Specifically, the letter w in English has three syllables, but only one in German. Conversely, $\mathrm{y}$ in English is one syllable, while it is three in German.

Any German teacher knows that an important grammatical concept for learning German is understanding case, including various prepositions which take specific cases. Therefore, it can be helpful for students to memorize lists of prepositions to different songs so that they can begin to separate prepositions into distinct categories. For example, the accusative prepositions bis, durch, für, gegen, ohne, um can be sung to the first line of the tune Raindrops Keep Fallin' on my Head (by Hal David and Burt Bacharach). The dative prepositions aus, außer, bei, mit, nach, seit, von, zu, on the other hand, fit nicely with the tune of The Blue Danube by Johann Strauss. Finally, the two-way prepositions an, auf, hinter, in, neben, über, unter, vor, zwischen work well with the first two lines of Twinkle, Twinkle, Little Star.

It should be noted that L2 musical mnemonic devices are not restricted to grammar topics, or to German, for that matter. This will be discussed more thoroughly in section 4.4.

\subsection{Mnemonic Construction}

The following are four simple steps for composing a musical mnemonic device.

- Step 1: Select a portion of a popular or common song from the language you teach.

- Step 2: Decipher the syllabic structure or meter (how many syllables are in each line?).

- Step 3: Decide on a topic you want to teach. 
- Step 4: Compose lyrics to fit the syllabic structure, and negotiate tune adaptation, if necessary.

\subsection{Example of New Mnemonic Device}

One difficult aspect oflearning anyProto-Indo-European language is memorizing how to conjugate the verb to be. Learning German as an L2 is no exception to this. These facts prompted the authors to create a musical mnemonic device to help L2 German students memorize and retain the various conjugations of sein.

Step 1: The melody to An die Freude, from the fourth movement of Ludwig van Beethoven's 9th Symphony, which is also the melody used as the European Union Anthem, is well-known the world over. Lyrics, originally written by Friedrich Schiller, have been adapted and rewritten into many languages, including surfacing as the English Christian hymn Joyful, Joyful We Adore Thee (lyrics by Henry van Dyke). Although many L2 German learners know this melody intimately, they have no knowledge of where this melody originated nor its cultural significance both in Germany as well as in the field of music history. Therefore, this melody is an ideal candidate for introducing into the L2 classroom via a mnemonic device.

Step 2: The meter for An die Freude (both in English and German) is given in (7).

\begin{tabular}{|llll|}
\hline Freude, schöner Götterfunken, & 8 & Joyful, joyful, we adore Thee, \\
Tochter aus Elysium, & 7 & God of glory, Lord of love; \\
Wir betreten feuertrunken, & 8 & Hearts unfold like flow'rs before Thee, \\
Himmlische, dein Heiligtum! & 7 & Op'ning to the sun above. \\
\hline
\end{tabular}

Figure 9: (7) Meter for An die Freude

Step 3: As mentioned above, the topic for this particular mnemonic device is the German verb sein.

Step 4: The conjugated forms of sein fit nicely into the meter of An die Freude, as shown in (8) below. The present tense only takes up the first two lines of the melody, so the simple past (which students must also memorize), is included as text for the third and fourth lines. It should be noted that Tune Adaptation is applied to the fourth line in the form of addition. The original melody only has seven syllabic units; however, the verb conjugation requires nine. The addition of extra notes in the melody is indicated in boldface type.

For illustrative purposes, these new lyrics are given with the musical notation, as well as the English text, in figure 3.

One great aspect to including such a historic song such as An die Freude in the classroom is the opportunity for discussing culture with the students. The history of this melody was described in Step 1, and this important cultural 


\begin{tabular}{ll}
\hline ich bin, du bist, er, sie, es ist & 8 \\
wir sind, ihr seid, sie, Sie sind & 7 \\
ich war, du warst, er, sie, es war & 8 \\
wir waren, ihr wart, sie, Sie waren & 9
\end{tabular}

Figure 10: (8) New Musical Mnemonic for sein

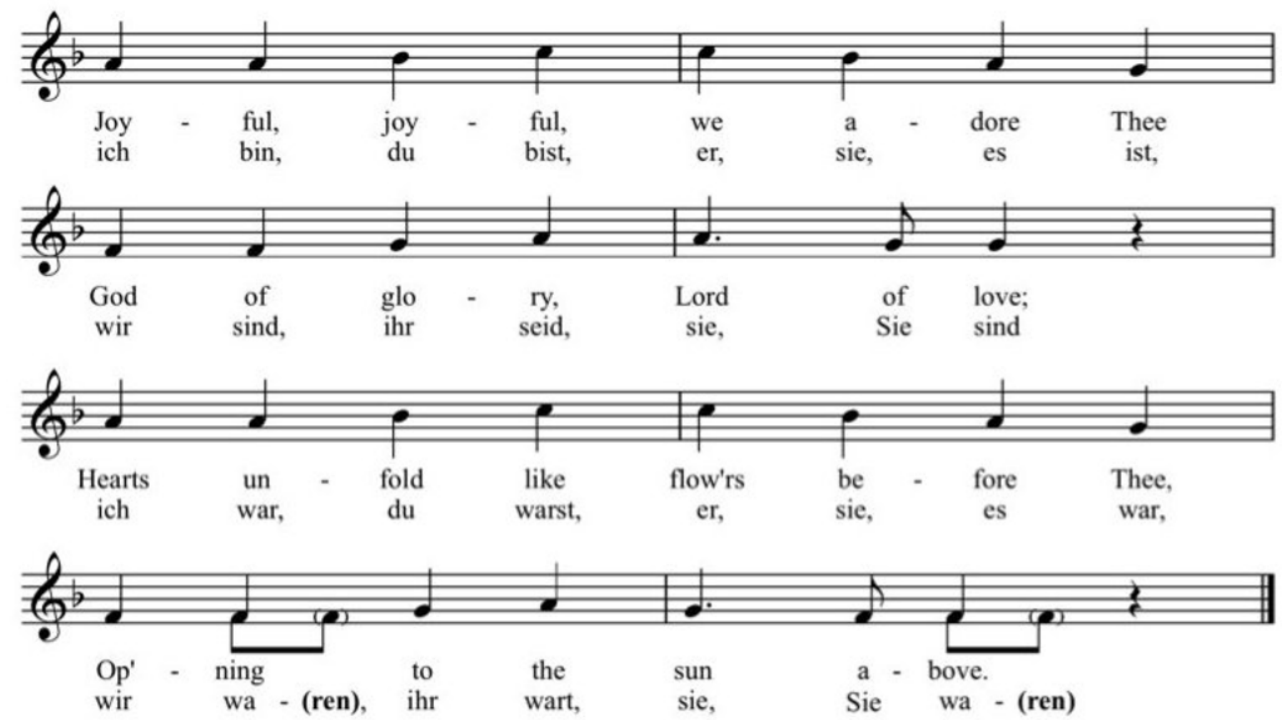

Figure 11: Musical Mnemonic for sein based on the hymn tune An die Freude often sung to the hymn text Joyful, Joyful, We Adore Thee

information can easily be woven into discussion before presenting this new mnemonic device.

\subsection{Further Ideas for Incorporating Musical Mnemonics}

In this section, additional ideas are presented for incorporating musical mnemonic devices into the L2 classroom. Interestingly, the literature on mnemonics cited throughout this article covers a large range of ages for learners, indicating that mnemonics are effective, regardless of a learner's age. It is the authors' belief that musical mnemonics can be efficacious with any age group and, as noted above, they can cover a multitude of topics, not simply grammar. For example, some participants in our workshop wrote a song about Falsche Freunde (false cognates) in German, while another group wrote a song about barnyard animal sounds in Japanese. Mnemonics can also be an excellent opportunity to include students in an interactive activity. Instructors can present students with the four simple steps above and assign students to create their own unique mnemonic devices (Nuessel 2007).

Musical mnemonics can be integrated as a central pedagogical or peripheral 
pedagogical element within course design. It is important to remember that singing in the classroom is performative, not performance; in other words, the efficacy of musical mnemonics is developed through engaging all students in a performative act, not in attaining an elite level of performance. Successful use of musical mnemonics does not hinge on innate musical ability or training. Musical expertise is not required in order to apply these principles; in fact, non-musicians are particularly encouraged to develop mnemonic songs for their classes.

Finding a good starting note is key for leading group singing. This note should allow the melody to reside in the mid portion of the voice, thereby avoiding notes that are too high or too low. Deciphering the apropos note should be done prior to class with either a pitch pipe (which can be found for free online or as a phone app) or an instrument. If teachers choose a less familiar tune (which can be a very important cultural addition to the class), lining-out technique can be particularly useful. To employ this technique, simply sing each line separately and cue the class to echo each line verbatim.

\section{Conclusion}

Every culture has its own unique musical expressions, and music is one of the most accessible portals for integrating culture in the L2 classroom. Additionally, mnemonics are a very useful tool for memorizing new concepts, and recent research has shown the long-term effects of pairing text and music to aid memorization. With the steps outlined in this paper, language teachers are equipped with the tools to incorporate endless language principles with music significant to the languages and cultures which they teach. This paper has sought to import the recent scholarly interest in mnemonics (Purnell-Webb \& Speelman 2008, Good et al. 2015, Putnam 2015, among others) into the field of performative pedagogy through one simple musical application. We believe there are likely many ways in which mnemonics apply within the field of performative pedagogy, including but not limited to music, theatre, and dance. Future research may explore application of mnemonics to a wide variety of art forms within the field of performative pedagogy.

\section{Bibliography}

Bill Selak (2009,

November 28): Wakko's50 State Capitols with Lyrics/Subtitles [Videofile].https://www.youtube.com/watch?v=MSvJ9SN8THE\&feature =youtu.be\&t=27 [last accessed June 30, 2018]

Bmusproject (2012, June 23): ABC Song Vs Twinkle Twinkle Little Star Split Screen [Video file]. https://www. youtube.com/watch?v=B_IRUrUC60 [last accessed June 30, 2018] 
Celtic Woman Official (2009, November 28): Celtic Woman - Amazing Grace [Video file]. https://www.youtube.com/watch?v=HsCp5L_zNE [last accessed June 30, 2018]

Classical Music Only (2008, September 17): Johann Strauss II - The Blue Danube Waltz [Video file].

https://www • youtube.com/watch?v_CTYymbbEL4 [last accessed June 30, 2018]

Frey-Clark, Marta (2017): Pitch systems and Curwen Hand Signs: A Review of Literature. In: Update: Applications of Research in Music Education 36/1, 59-65

Good, Arla J.; Russo, Frank A. \& Sullivan, Jennifer (2015): The efficacy of singing in foreign-language learning. In: Psychology of Music 43, 627-640

Hymn Accompaniments (2014, August 7): Doxology (Tune: Old 100th) [Video file]. https: / /www.youtube.com/watch?v=ygBnzM1JBWM [last accessed June 30, 2018]

Killam, Rosemary (1988): Solmization with the Guidonian Hand: A Historical Introduction to Modal Counterpoint. In: Journal of Music Theory Pedagogy $2 / 2,251-274$

Livesey, Laetitia; Morrison, Ian; Clift, Stephen \& Camic, Paul (2012): Benefits of choral singing for social and mental wellbeing: Qualitative findings from a cross-national survey of choir members. In: Journal of Public Mental Health 11/1, 10-26

Nuessel, Frank (2004): Mnemonic Acronyms: A Memory Aid for Teaching and Learning Spanish Grammar. In: Mosaic 8/2, 21-24

Packard, Noel \& Chen, Christopher (2005): From medieval mnemonics to a social contruction of memory: Thought on some early European conceptualizations of memory, morality, and consciousness. In: American Behavioral Scientist 48/10, 1297-319

Purnell-Webb, Patricia \& Speelman, Craig P. (2008): Effects of Music on Memory for Text. In: Perceptual and Motor Skills 106, 927-957

Putnam, Adam L. (2015): Mnemonics in education: Current research and applications. In: Translational Issues in Psychological Science 1/2, 130-139

Truthorfable (2009, July 23): Gilligan's Island Theme Song [Video file]. https://www.youtube.com/watch?v=yfSLuEj99do [last accessed June 30, 2018]

TV80s (2015, May 1): Nena - 99 Luftballons [Video file]. https://www.youtube.com/watch?v=La4DcdlaUcE [last accessed June 30, 2018]

TheBJThomas (2015, February 24): Raindrops Keep Falling on My Head [Video file]. https://www youtube.com/watch?v=SYSIY1XKIhM [last accessed June 30, 2018]

Vatri, Alessandro (2015): Ancient Greek writing for memory: Textual features as mnemonic facilitators. In: Mnemosyne 68/5, 750-773 
Watson, J. R. (1999): The English hymn: A critical and historical study. Oxford: Oxford University Press

Yates, Frances (1996): The art of memory. Chicago, IL: The University of Chicago Press 